\title{
Phytochemical Screening of Two Tropical Moss Plants: Thidium gratum P. Beauv and Barbula indica Brid Grown in Southwestern Ecological Zone of Nigeria
}

\author{
Adedeji O. Adebiyi ${ }^{1}$, Ayodele A. Oyedeji ${ }^{1,2,3^{*}}$, Elijah E. Chikwendu ${ }^{1}$, Olubunmi A. Fatoke ${ }^{4}$ \\ ${ }^{1}$ Department of Plant Science, Ekiti State University, Ado Ekiti, Nigeria \\ ${ }^{2}$ Department of Biological Sciences, Niger Delta University, Wilberforce Island, Nigeria \\ ${ }^{3}$ Environmental and Analytical Sciences Laboratory, Department of Biological Sciences, School of Applied Sciences, \\ University of Wolverhampton, Wolverhampton, UK \\ ${ }^{4}$ Department of Chemistry Education Science, Ekiti State University, Ado Ekiti, Nigeria \\ Email: *ayodele.oyedeji@yahoo.com
}

Received September 25, 2012; revised October 25, 2012; accepted November 6, 2012

\begin{abstract}
Chemical tests were carried out on the aqueous extracts of the air-dried powders of two tropical moss plants, Thidium gratum and Barbula indica using standard procedures, to identify the phytochemical constituents. The extracts were screened for the presence and quantities of alkaloids, flavonoids, phenols, saponins and steroids with a view to assess their therapeutic values in ethnomedicine. The results of the phytochemical screening revealed the presence of alkaloids, flavonoids, phenols, saponins and steroids in varying quantities in the two moss plants but there was absence of phenol in Barbula indica. These results suggest that the two moss plants can be veritable and potential source of useful drugs in treatment of ailments.
\end{abstract}

Keywords: Phytochemical Constituents; Extracts; Moss Plants; Ethnomedicine; Ailments

\section{Introduction}

Mosses are small non-woody plants that are typically 1 $10 \mathrm{~cm}$ tall, though some species are much larger. They belong to the division bryophyta. It is estimated that there are about 25,000 bryophyte species known in the world which consist of three separate divisions, the Marchantiophyta (liverwort), Anthocerotophyta (hornworts) and Bryophyta (mosses) [1]. Bryophytes are found in all ecosystems except marine and their ecological roles in any ecosystem are significant [2]. Although, bryophytes normally grow in humid or damp habitats, they are relatively free from microbial attacks which indicate that they are able to elaborate constitutive small molecule antimicrobials.

Very little is known about the chemistry of bryophytes particularly at molecular level [3-5] and information concerning research results is very scattered. The reasons for this are the difficulties researchers have with bryophyte identification, the limited amount of the same species available for analyses due to their inconspicuous position in the ecosystem and the difficulty with which analysis can be conducted since it relies on sophisticated method.

*Corresponding author.
Results of phytochemical screening of many higher plants are widely available $[1,5,8]$.

Although bryophytes have been proven to be a rich source of antibiotics [20], very few studies concerning the biologically active constituents in them have been published [3,4,10,14,17].

This study was designed to determine the phytochemical constituents of two tropical moss plants, Thidium gratum and Barbula indica with a view to assess their therapeutic values in ethnomedicine.

\section{Materials and Methods}

\subsection{Collection and Identification of Plant Materials}

Thidium gratum was collected on the bark of a tree (Mascularia acuminata) in the bank of Elemi River in Ilokun village, Ado-Ekiti while Barbula indica was collected from the wall of a building in Ado-Ekiti, Ekiti State, Nigeria. The two moss plants were identified at the Herbarium Unit of the Department of Plant Science, Ekiti State University, Ado-Ekiti, Nigeria. Voucher specimens were deposited in the Herbarium. The two moss plants were air dried and ground into powder separately using 
an electric blender and finally stored in air tight bottles at $37^{\circ} \mathrm{C}$.

\subsection{Phytochemical Screening}

Chemical tests were carried out on the aqueous extracts and powdered specimens using standard procedures to identify the chemical constituents as described by $[12,18]$.

\subsection{Preparation of Fat Free Sample}

$2 \mathrm{~g}$ of each plant sample was defatted with $100 \mathrm{ml}$ of ethanol using a soxhlet apparatus for 2 hours.

\subsection{Test for Flavonoids}

$5 \mathrm{ml}$ of dilute ammonia solution were added to a portion of the aqueous filtrate of each plant extract followed by addition of concentrated $\mathrm{H}_{2} \mathrm{SO}_{4}$. A yellow colouration observed in each extract indicated the presence of flavonoids. The yellow colouration disappeared on standing [18].

\subsection{Test for Saponins}

$2 \mathrm{~g}$ of the powdered sample of each plant was boiled in $20 \mathrm{ml}$ of distilled water in a water bath and filtered $10 \mathrm{ml}$ of the filtrate was mixed with $5 \mathrm{ml}$ of distilled water and shaken vigorously for a stable, persistent froth. The froth was mixed with 3 drops of olive oil and shaken vigorously, and then observed for the formation of emulsion.

\subsection{Test for Steroids}

$2 \mathrm{ml}$ of acetic anhydride was added to $0.5 \mathrm{ml}$ of ethanol extracts of each sample with $2 \mathrm{ml} \mathrm{H}_{2} \mathrm{SO}_{4}$. The colour changed from violet to blue indicating the presence of steroids.

\subsection{Determination of Total Phenols}

The fat free sample was boiled with $50 \mathrm{ml}$ of ether for the extraction of the phenolic component for 15 minutes. $5 \mathrm{ml}$ of the extract was pippetted into $50 \mathrm{ml}$ flask; $10 \mathrm{ml}$ of distilled water was added. $2 \mathrm{ml}$ of ammonium hydroxide solution and $5 \mathrm{ml}$ of ethanol were added. The samples were made up to the mark and left to react for 30 minutes for colour development. The absorbance of the solution was read using spectrophotometer at $505 \mathrm{~nm}$ wavelength [12].

\subsection{Determination of Alkaloids}

$1.25 \mathrm{~g}$ of the sample was weighed into $250 \mathrm{ml}$ beaker and $50 \mathrm{ml}$ of $10 \%$ acetic acid was added. It was covered and allowed to stand for 4 hours. This was filtered and the extract was concentrated using a water bath to one quar- ter of the original volume. Concentrated ammonium hydroxide was added dropwise to the extract until the precipitation was complete. The whole solution was allowed to settle and the precipitate was collected and washed with dilute ammonium hydroxide and then filtered. The residue is the alkaloid. It was dried and weighed [12].

\subsection{Determination of saponins}

$5 \mathrm{~g}$ of the sample was put in a conical flask. $25 \mathrm{ml}$ of $20 \%$ aqueous ethanol were added. The sample was heated over a hot water bath for 4 hours with continuous stirring at about $55^{\circ} \mathrm{C}$. The mixture was filtered and the residue re-extracted with another $50 \mathrm{ml}$ 20\% ethanol. The combined extracts were reduced to $10 \mathrm{ml}$ over water bath at about $90^{\circ} \mathrm{C}$. The concentrate was transferred into a 250 $\mathrm{ml}$ separatory funnel and $5 \mathrm{ml}$ diethyl ether was added and shaken vigorously. The aqueous layer was recovered while the ether layer was discarded. The purification process was repeated $15 \mathrm{ml}$ of ethanol was added. The combined ethanol extracts were washed twice with 2.5 ml of $5 \%$ aqueous sodium chloride. The remaining solution was heated in a water bath. After evaporation, the sample was dried in the oven to a constant weight and the saponin content was calculated as percentage [12].

\subsection{Determination of Flavonoids}

$5 \mathrm{~g}$ of the moss plant samples were extracted repeatedly with $50 \mathrm{ml}$ of $80 \%$ methanol at room temperature. The whole solution was filtered through Whatman filter paper No. 42 (125 mm). The filtrate was later transferred into a crucible and evaporated to dryness over a water bath and weighed by the methods adopted by [8].

\section{Results}

The results of the qualitative phytochemical screening of the two moss plants indicated the presence of medically active constituents such as alkaloids, flavonoids, phenols, saponin and steroids. Phenol was absent in Barbula indica. The phytochemical characters of the moss plants are as summarized in Tables $\mathbf{1}$ and $\mathbf{2}$.

The quantitative estimation of the percentage crude chemical constituents in the two moss plants is summarized in Table 2. All the phytochemical constituents are of higher percentage crude yield in Barbula indica except for phenol which could not be detected in it. However, the quantity of phenols obtained in Thuidium gratum was minimal (0.055\%).

\section{Discussion}

The results of the phytochemical screening and quantitative estimation of the chemical constituents of the two 
Table 1. Qualitative analysis of the phytochemicals of the moss plants investigated.

\begin{tabular}{cccccc}
\hline Moss plant & Steroids & Phenol & Saponin & Flavonoids & Alkaloids \\
\hline T. gratum & + & + & + & + & + \\
B. indica & + & - & + & + & + \\
\hline
\end{tabular}

Table 2. Percentage of phytochemicals present in the moss plants investigated.

\begin{tabular}{ccccc}
\hline Moss plants & Alkaloids & Phenol & Saponin & Flavonoids. \\
\hline & $(\%)$ & $(\%)$ & $(\%)$ & $(\%)$ \\
T. gratum & 1.60 & 0.055 & 14.40 & 10.00 \\
B. indica & 5.60 & - & 17.80 & 12.00 \\
\hline
\end{tabular}

moss plants have indicated high contents of flavonoids, saponin and alkaloids. The percentage quantity crude yield of phenols obtained in this study (0.055\%) is lower than those obtained by $[6,7]$ who worked on the phytochemical screening of some medicinal higher plants. But the value tends to agree with those obtained in $S$. dulcis $(0.04 \%)$, S. acuta $(0.08 \%)$ and $T$. procumbens $(0.06 \%)$ in a research investigated by [7].

However, the values obtained for saponin are higher than those obtained by [6,7] while the values obtained for flavonoids in this study tend to agree with the results obtained by [6]. The value obtained for alkaloids in $T$. gratum was comparable to that of $S$. acuta in [7] and $P$. crassipes in [6] while the value obtained for $B$. indica is comparable to S. augustifolia in [6].

Steroids were found to be present in the two moss plants. It is worthy of note that steroidal compounds are of importance and interest in pharmacy due to their relationship with such compounds as sex hormones [15]. Research reports have it that, the presences of these phytochemical constituents suggest medicinal values [18-20]. Therefore, the moss plants can be seen as a potential source of useful drugs and drug additives both in ethnomedicine and synthetic drugs production. The antimicrobial activities of these plants are currently being investigated.

\section{REFERENCES}

[1] B. Goffinet and A. J. Shaw, "Bryophyte Biology,” Cambridge University Press, Cambridge, 2009, p. 565.

[2] K. Saxena and S. Harrinder, "Uses of Bryophytes," Resonance, Vol. 9, No. 6, 2004, pp. 56-65. doi:10.1007/BF02839221

[3] O. Ucuncu, T. B. Cansu, T. Ozddemir, K. S. Alpay and N. Yayli, "Chemical Composition and Antimicrobial Activity of Essential Oils of Mosses (Tortula muralis Hewd., Homalothecium lutescens Hewd., Hypnum cupressiforme
Hewd. and Pohlia nutans Hewd.) from Turkey,” Turkish Journal of Chemistry, Vol. 34, 2010, pp. 825-834.

[4] N. Jockovic, P. B. Andrade, P. Valentao and M. Sabovljevic, "HPLC-DAD of Phenolics in Bryophytes Lunularia cruciate, Brachytheciastrum velutinum and Kindbergia praelonga," Journal of the Serbian Chemical Society, Vol. 73, No. 12, 2008, pp. 1161-1167. doi:10.2298/JSC0812161J

[5] Y. Asakaw, "Recent Advances in Phytochemistry of Bryophytes-Acetogenins, Terpenoids and Bis(Bibenzyl)s from Selected Japanese, Taiwanese, New Zealand, Argrntinean and European Liverworts," Phytochemistry, Vol. 56, No. 3, 2001, pp. 297-312. doi:10.1016/S0031-9422(00)00454-4

[6] A. B. Aliyu, A. M. Musa, J. A. Oshanimi, H. A. Ibrahim and A. O. Oyewale, "Phytochemical Analyses and Mineral Elements Composition of Some Medicinal Plants of Northern Nigeria,” Nigerian Journal of Pharmaceutical Sciences, Vol. 7, No. 1, 2008, pp. 119-125.

[7] H. O. Edeoga, D. E. Okwu and B. O. Mbaebie, "Phytochemical Constituents of Some Nigerian Medicinal Plants," African Journal of Biotechnology, Vol. 4, No. 7, 2005, pp. 685-688.

[8] B. A. Boham and A. C. Kocipai, "Flavonoids and Condensed Tannins from Leaves of Hawaiian Vaccinium vaticulatum and V. calycinium," Pacific Science, Vol. 48, No. 4, 1974, pp. 458-463.

[9] C. F. Xie and H. X. Lou, "Secondary Metabolites in Bryophytes: An Ecological Aspect," Chemistry \& Biodiversity, Vol. 6, No. 3, 2009, pp. 303-312. doi:10.1002/cbdv.200700450

[10] B. Elibol, T. Ezer, R. Kara, C. Yuvali and E. Colak, “Antifungal and Antibacterial Effects of Some Acrocarpic Mosses," African Journal of Biotechnology, Vol. 10, No. 6, 2011, pp. 986-989.

[11] R. G. Bodade, P. S. Borkar, A. M. Saiful and C. N. Khobragade, "In-Vitro Screening of Bryophytes for Antimicrobial Activity," Journal of Medicinal Plants Research, Vol. 7, No. 4, 2008, pp. 23-28.

[12] M. Singh, A. K. S. Rawat and R. Govindarajan, “Antimicrobial Activity of Some Indian Mosses,” Fitoterapia, Vol. 78, No. 2, 2007, pp. 156-158. doi:10.1016/j.fitote.2006.10.008

[13] S. Lihan, F. Savaroglu, F. Colak, I. C. Filik and F. Z. Erdemgil, "Antimicrobial Activity of Palustriella commutate (Hewd.) Ochyra Extracts (Bryophyta),” Turkish Journal of Biology, Vol. 30, 2006, pp. 149-152.

[14] A. Basile, S. Giordano, S. J. A. Lopez and R. C. Cobianchi, "Antibacterial Activity of Pure Flavonoids Isolated from Mosses,” Phytochemistry, Vol. 52, No. 8, 1999, pp. 1479-1482. doi:10.1016/S0031-9422(99)00286-1

[15] A. A. Sofowora, "Medicinal Plants and Traditional Medicine in Africa," 2nd Edition, Spectrum Books Ltd., Ibadan, 1993, pp. 81-85.

[16] J. B. Harborne, "Phytochemical Methods: A Guide to Modern Techniques of Plant Analysis,” Chapman and Hull Ltd., London, 1973, pp. 49-188.

[17] D. E. Okwu, "Evaluation of the Chemical Composition of 
Indigenous Spices and Flavouring Agents," Global Journal of Pure and Applied Sciences, Vol. 7, No. 3, 2001, pp. 455-459.

[18] A. Del-Rio, B. G. Obdululio, J. Casfillo, F. G. Marin and A. Ortuno, "Uses and Properties of Citrus Flavonoids," Journal of Agricultural and Food Chemistry, Vol. 45, 1997, pp. 4505-4515. doi:10.1021/jf970373s
[19] M. M. Cowman, "Plant Products as Antimicrobial Agents," Clinical Microbiology Review, Vol. 12, No. 4, 1999, pp. 564-582.

[20] H. O. Edeoga and D. O. Eriata, "Alkaloids, Tannin and Saponin Contents of Some Nigerian Medicinal Plants," Journal of Medicinal and Aromatic Plant Sciences, Vol. 23, 2001, pp. 344-349. 